\title{
Un estudio desde la Mediación cultural: Las representaciones evocadas por el público en una exposición de arte contemporáneo colombiano en París
}

\author{
Cristina Vargas Pacheco?
}

Universidad de Piura

La concepción de toda exposición, sea cual sea su temática, supone la creación de un discurso que es propuesto a los visitantes. Sin embargo, entre el discurso académico concebido por los comisarios de la exposición y la lectura que el público hará del mismo, una serie de operaciones mentales son puestas en funcionamiento por este, a fin de acortar las múltiples "distancias" existentes e intentar recrear el sentido semántico de la proposición cultural.

El presente artículo se interesa, entonces, por las representaciones mentales que una exposición que reunió la obra de cuatro artistas contemporáneos colombianos, sugirió en los públicos asistentes al Museo du Quai Branly en París -latino o europeo; habitual o experto...-, presentando algunos métodos que nos permiten acercarnos a ellas y explorarlas. De esta manera, se inserta dentro del panorama de la Mediación cultural y sus múltiples propuestas en pos de cumplir el rol de "puente" entre dos de los elementos fundamentales de toda exposición: el visitante y la colección.

Discurso expositivo / Representaciones / Visitantes / Arte contemporáneo / Colombia, París / Libro de visitantes.

The meaning of an exhibition, no matter what the theme is, implies a particular kind of speech offered to the visitors. However, between the academical speech created by the curators and how the visitors understand it, a series of mental operations starts to roll in order to reduce the "distances" and recreate the semantical sense of cultural proposition. This article attends the mental representations suggested in different kinds of visitors -Latin American or European, amateur or expert...-, by an exposition in Quai Branly Museum in Paris, which joined the work of four Colombian contemporary artists. The analyze of representations carries on several methods which allow its exploration, and, as a consequence, it is included in the Cultural Mediation and its different purposes, like to bridge between the two fundamental elements of an exhibition: visitor and collection.

\section{Speech / Representations / Visitors / Contemporary Art / Colombia / Paris / Museums} guest book.

Mediación cultural en el contexto francófono

La Mediación cultural ha sido definida en la obra "Conceptos claves en Museología" como "[...] toda una gama de intervenciones llevadas a cabo en el contexto museal, destinadas a establecer puentes entre lo que está expuesto (ver) y el significado que dichos objetos y sitios pueden revestir (saber)"'. O'Neill afirma que la imagen más le recuerda la función

1 Desvallées, André y Maraisse, François (dir.). "Conceptos claves en Museología”. (2010) http://icom.museum/ fileadmin/user_upload/pdf/Key_Concepts_of_Museology/Museologie_Espagnol_BD.pdf [Consulta: 20 julio 2014], p. 47. 
que cumple la Mediación en el contexto museal, es la de una "escalera" pues esta permite al visitante "ir más alto, ir más lejos" en los conocimientos que este traía a las salas de exposición.

Así, en el contexto francófono, la Mediación cultural ha adquirido una mayor atención dentro de las prácticas habituales del mundo de la cultura, desterrándose la idea que el corazón de una exposición o un museo, son únicamente los musealium o las "cosas verdaderas", como definiera Duncan Cameron a los objetos musealizados. De hecho, en Francia, la Ley museo del año 2002 -hoy inserta en el Code du Patrimoine (2004)-, reafirma la importancia acordada a los visitantes, en todo museo que lleva la marca "Musée de France". Por ende, según esta legislación, los Musées de France, tienen por misión permanente, "el conservar, restaurar, estudiar e incrementar sus colecciones; pero también, el hacerlas accesibles al público más amplio posible" (Trad. Pers.) De igual manera, se señala que tienen por misión continua la de "concebir y llevar a cabo, acciones de educación y de difusión, con el objetivo de asegurar un acceso igualitario a la cultura" (Trad. Pers.), pues esta es entendida, desde la Revolución Francesa, como un servicio público que debe ser garantizado por el Estado. La misma Ley señala que cada Musée de France "dispone de un servicio que tiene a cargo las acciones de recepción de público, de difusión, de animación y de mediación cultural" (Trad. Pers.), acciones que son garantizadas por personas calificadas. Así, la importancia dada a los diversos visitantes, adquiere un nivel similar al de la conservación, exhibición, entre otras ya tradicionales a la institución.

De allí la importancia cobrada por los Servicios culturales y educativos, y los estudios en Mediación cultural. Dentro de las amplias perspectivas de investigación que este campo permite, aquellas orientadas hacia la comprensión del funcionamiento psicológico y social del visitante y la utilización de la imaginación, han sido largamente trabajadas en el contexto canadiense y francés, particularmente por Dufresne-Tassé y Heinich, respectivamente. Para acercarnos a ese aspecto tan complejo del comportamiento de los visitantes, varios métodos prestados a la sociología, la psicología, entre otras ciencias humanas, han sido ensayados, como: la entrevista semi-dirigida, el cuestionario, el "pensar a viva voz" (penser tout haut) y, quizás uno de los más complejos y fascinantes, el análisis del libro de visitantes.

\section{La exposición Nocturnes de Colombie. Images contemporaines}

Nuestro trabajo se centra en el análisis de un caso concreto: la exposición Nocturnes de Colombie. Images contemporaines (Nocturnos de Colombia. Imágenes contemporáneas), realizada en el Museo parisino du Quai Branly, entre el 17 de septiembre de 2013 y el 2 de febrero de 2014, dentro del marco de la cuarta edición de la Bienal de fotografía del mundo, Photoquai. Cabe destacar que casi en simultáneo, hubo en París una rica oferta de exposiciones reuniendo a artistas latinoamericanos, a saber: Vagabondages, consagrada a Sergio Larraín (Fondation Cartier-Bresson, 11 de septiembre- 22 de diciembre 2013); Genesis, sobre la obra de Sebastião Salgado (Maison Européenne de la Photographie, 25 de septiembre 2013- 05 de enero 2014); así como la mediatizada, Frida Kahlo, Diego Rivera. L'art en fusión (Musée de l'Orangerie, 8 de octubre 2013- 13 de enero 2014). El Instituto Cervantes presentó Mírame Lima (17 octubre - 15 noviembre 2013); y, finalmente, se inauguró la ambiciosa exposición América Latina. 1969-2013. Photographies, realizada en la Fondation Cartier pour l'art contemporain (19 noviembre 2013 - 6 abril 2014).

Nocturnes de Colombie fue comisariada por Christine Barthe, responsable de la sección de fotografía del Museo du Quai Branly. ${ }^{2}$ La muestra reunió en cuatro secciones diferenciadas, pero bajo el mismo título, a cuatro artistas colombianos, ya consagrados en la escena

2 Quien gentilmente nos permitió la realización del presente estudio. 
contemporánea: Juan Manuel Echavarría, José Alejandro Restrepo, Miguel Ángel Rojas y Óscar Muñoz. El hilo conductor del discurso propuesto se hilvana a partir de un hecho histórico ocurrido el 9 de abril de 1948: el asesinato del líder político Jorge Eliécer Gaitán, acontecimiento doloroso que dará inicio al período de la historia colombiana denominado

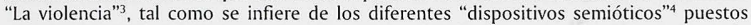
a disposición del público (textos escritos en carteles de diverso tipo ${ }^{5}$, un documento de ayuda a la visita, así como la revista que cumplió el rol de una suerte de catálogo de esta muestra). Los artistas colombianos habrían sido reunidos en virtud de ese interés compartido por la experimentación con la imagen, con propuestas que abarcan el video arte y la fotografia; pero además (y tomando en consideración las obras seleccionadas para esta exposición), en virtud de una inspiración compartida que se ancla en las "violencias multiformes" -como se explicó en la muestra-, que desde entonces se han vivido en Colombia y que están en vía de superación, también por la vía de la cultura. ${ }^{6}$ En ese sentido, ellos ya habían sido reunidos (aunque considerando además a otros artistas colombianos), en muestras realizadas en Casa Daros, tanto en Zurich, así como en Río de Janeiro. ${ }^{7}$ En estas muestras, fueron definidos como artistas pertenecientes a una "generación intermedia" que bebe su inspiración en una "historia y un presente doloroso"8. De esta manera, vemos que la coherencia temática de la exposición fue también buscada, en esa "belleza deletérea [inspirada] en la violencia y en la muerte", de la que habla Durán, y que en estos artistas tendría por objetivo de generar una reflexión en el espectador. Dicho esto, ¿qué motivó, entonces, la elección de estos cuatro artistas y no de otros? ¿Esa elección, revelaría una visión también subyacente en el imaginario francés, construida en larga duración, sobre la América Latina y, particularmente, sobre Colombia ${ }^{10} \mathrm{¿O}$ es que, por el contrario, simplemente transparenta una de las temáticas reiterativas de la plástica colombiana, tal como ya lo ha manifestado el crítico colombiano, José Roca?" ${ }^{11}$, en todo caso, esto llevaría también a preguntarnos, ¿qué efecto tuvo la elección de estos artistas en los diversos públicos? De hecho y solo por poner un ejemplo, de los 464 comentarios identificados en el Libro de

3 Sobre este punto, resulta útil revisar la monumental obra de Sader y Jinkings (Coord.), Latinoamericana. Enciclopedia contemporánea de América Latina y el Caribe, 2008, que para el caso del país de los artistas, incluye una entrada bajo el título de "Violencia en Colombia».

4 Cf. Poli, Houbart, en, Eidelman, Roustan, Goldstein, 2007, 185-198.

5 Hubo panel de introducción, paneles de sección, carteles desarrollados (allongés o developpés) y etiquetas (cartela o notice d'cuvre).

6 En efecto, tal como se lee en la revista Hors-série Beaux Arts magazine. Nocturnes de Colombie, la comisaria de la exposición responde a la pregunta u¿De dónde viene este título Nocturnos de Colombia?, lo siguiente: "Yo no queria un título muy pedagógico o ilustrativo, entonces pensé en una novela de Roberto Bolaño, el famoso autor chileno de los Detectives salvajes, que se intitula Nocturno de Chile. De hecho, la idea de nocturno no es extraña a ciertas obras que exponemos y porta en ella, una gran fuerza evocadora. Además, el título Nocturno de Chile es un homenaje de Bolaño al escritor colombiano José Asunción Silva, a quien le debemos numerosos poemas melancólicos". Revue Hors- série, op. cit., p. 9 (Trad. Pers.).

7 Para mayor información, se puede consultar la página de internet de Casa Daros: http://www.daroslatinamerica.net/index_zh.php?i=941

8 «Cantos Cuentos Colombianos». Exposición en Casa Daros, Rio de Janeiro (Brasil), 23 marzo- 08 septiembre 2013. http://www.daros-latinamerica.net/index_zh.php?q=1370 [Consulta: 15 abril 2014].

9 Cf. Durán, 2009, 147.

10 Sobre este punto, se puede consultar el artículo de Fanchon Deflaux aLa construction des représentations de l'art et des artistes non occidentaux dans la presse à la suite d'une exposition d'art contemporain*. 2004. Culture \& Musées. 3: 45-68. De igual manera, sobre la imagen de América asociada a la violencia, abordado en una perspectiva de larga duración, el artículo de Pascal Mongne. 2001. "La paille et la poutre: les images de la violence dans les Amériques". Cahiers des Amériques Latines. 38: 19-38.

11 Roca ha puntualizado sobre dicho tema con estas palabras: "Artistas, curadores, críticos, en cierto modo todos, así como hemos sufrido la violencia, de carambola también nos hemos beneficiado de eso, porque tenemos como un tema del cual hablar con propiedad, el cual, a la vez que es un cliché de la forma en que nos ven, también es pues, no es una casualidad todo el desarrollo de literatura, de cine y de arte en torno a este tema". Documental Plástica. Arte contemporáneo en Colombia. "Lo que puede un cuerpo: performancen. Cap. 7. (2004). http://youtu.be/OOUKcZiOS-g Ministerio de Cultura de Colombia. El vicio producciones. |Consulta: 15 abril 2014|. 
visitantes (manifestados en más de 5 idiomas distintos; así como por medio de dibujos), encontramos verbatim que reflejan reacciones a favor y en contra de la institución, pero también apelaciones hechas a los artistas solicitándoles la presentación de obras inspiradas en una realidad "más actual" - percibida como positiva- del país.

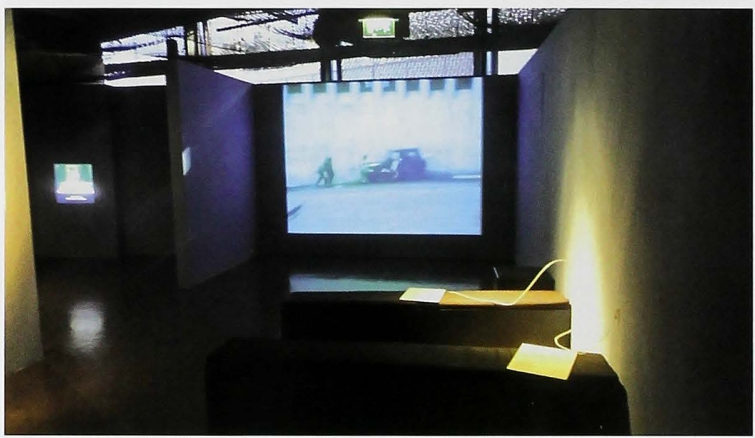

Fig. 1.- Obra (video-arte) de José Alejandro Restrepo: El caballero de la fe (2011). Fotografia de C.V.P.

La exposición, no obstante, fue principalmente una manera de descubrir una pequeña porción de la vasta producción colombiana, al público francés, tal como lo explicó la comisaria. ${ }^{12}$ Por dicha razón, la información se proporcionó en dos lenguas: francés e inglés. El hecho de consignar información en el segundo idioma tiene que ver con ser considerado uno de uso universal. Esta elección implicó que, a medida que nos acercábamos a la obra de arte, el nivel de mediación escrita disminuía, pues los carteles de obra solo se presentaban en francés, incluyendo únicamente el nombre de la obra en español. Lo que quedó claro tras este estudio es que hubo una presencia, si bien no numerosa, sí importante (por su deseo de visibilización, reconocible por su manifestación en el Libro de visitantes (en adelante LdV)), de origen latinoamericano y, principalmente, colombiano. Evidentemente una parte de este público lamentó la ausencia de información en español (1,29\% del público que dejó un comentario), aunque muchos de ellos también intentaron "interactuar" con el museo, al manifestarse en francés (tal como una vez más lo revelaron los comentarios del Libro de visitantes:

12.1.2014 Gracias por esta exposición. Soy colombiana y creo, es importante mostrar la reflexión y el trabajo de 4 grandes artistas sobre nuestra realidad, nuestra historia. No comparto la idea de otras personas que dicen que sólo se muestra lo negativo: justamente esas opiniones reflejan la negación de lo que somos también y el arte es uno de los medios para mostrarlo y activar nuestra amnesia. Hubiera sido pertinente que la exposición hubiera también sido traducida al Español. C' est dommage!. (LdV) ${ }^{13}$.

12 Cf. Revista Hors série. Nocturnes de Colombie.

13 Los comentarios han sido retomados tal y como fueron vertidos, tanto en el idioma en que el visiteur-scripteur se manifiesta, como en las faltas ortográficas o gramaticales que presenta. El subrayado es nuestro. 


\section{Las representaciones que sugiere una exposición de arte contemporáneo}

Múltiples tipos de comentarios (satisfacción, insatisfacción, comprensión...) y representaciones construidas, se identificaron en el público asistente. Cabe precisar, entonces, lo que nosotros comprendemos por representación. Esta ha sido definida, de manera general, como

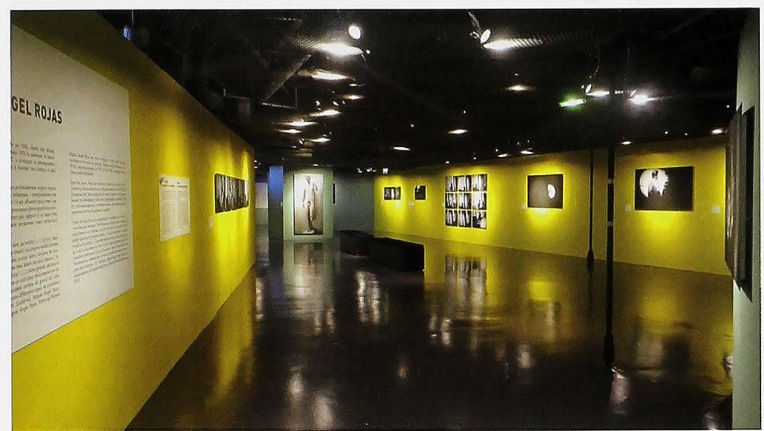

Fig. 2.- Espacio consagrado a la obra de Miguel Ángel Rojas. Al fondo se aprecia la obra David 1 (2004). Fotografia de C.V.P.

"la acción de evocar algo, alguien, por el lenguaje", constituyendo una suerte de "... / mediación [pues] da presencia a aquel que no puede estar presente"'4. En ese sentido, las representaciones fabricadas por el público, no son otra cosa que las significaciones que los visitantes produjeron sobre las imágenes (obras) a las que fueron confrontados, para, en seguida y en varios casos, elaborar otros significados sobre la integridad de la propuesta cultural. Apelando a la psicología social, Serge Moscovici resume el complejo concepto de representación en la fórmula: "figura/significación". 15 De manera que "representar" algo, no es solo reproducir en nuestra mente la imagen ofrecida, sino repensarla a nuestra manera. En ese sentido, si toda exposición es un "dispositivo mediático" o un "média" - según palabras de Davallon- ${ }^{16}$, ¿qué representaciones podrían construir los visitantes que acudieron a Nocturnes de Colombie. Images contemporaines? Tal como lo ha explicado Dufresne-Tassé para sus estudios realizados en Canadá, para comprender las representaciones -o la imaginación empleada por el visitante-, hay que tener en cuenta dos elementos: la cultura transmitida por el museo y aquella traída por el visitante. Y es precisamente en este último punto en que vemos que el visitante puede venir al museo o la sala de exposición con conocimientos (obtenidos en los medios de comunicación o de mayor anclaje intelectual) o elementos afectivos, todos los cuales podrían afectar o modificar las diferentes percepciones posibles de la proposición cultural. ${ }^{17}$

Volviendo sobre la imaginación, concepto que ingresa dentro del ámbito del funcionamiento psicológico del visitante, la investigadora canadiense explica que esta no se produce en

14 Encyclopédie Larousse, http://www.larousse.fr/encyclopedie/divers/repr\%C3\%A9sentation/87634 (Trad. Pers.) [Consulta: 05 febrero 2014].

15 Cf. Moscovici, 2004.

16 Davallon, 1992: 110.

17 Cf. Dufresne-Tassé, Sauvé, Banna et alii. En Dufresne- Tassé, 2000, 137 y ss. 
el visitante, sin que el funcionamiento afectivo o cognitivo hagan su aparición previamente. Entonces, si los objetos o las imágenes a las que son confrontados los visitantes no son acompañados de una debida mediación que les ayude a acortar las distancias existentes (cognitiva, física, etc.), no podrán llegar al nivel de la imaginación y, por ende, sus representaciones no necesariamente irán acordes al objetivo buscado por la exposición. En ese sentido, parece un hecho que el correcto "acompañamiento" le ayudará a salir de la situación del "rendez-vous manqué" - del que habla Dufresne-Tassé-, permitiéndole ir "más lejos" y reaccionar psicológicamente de manera creativa o, como ella misma lo denomina, realizando un "diálogo constante".

\section{Mediación del arte contemporáneo ¿por qué?}

Christian Bernard, en un artículo sobre la mediación del arte contemporáneo, explica el gran reto que implica acercar y facilitar la comprensión de las obras de arte en el público general no experto y, particularmente al visitante solitario. Una de las soluciones que el investigador propone, es la inclusión de carteles développés (desarrollados), donde el grado de información brindada al visitante será mayor. Ello haría más enriquecedor el jonglage ${ }^{18}$, permitiéndole al visitante la construcción de una mejor comprensión de lo visto.

Al parecer, muchos de los "rechazos" identificados por Heinich hacia el arte contemporáneo, son producto pues, de la incomprensión de la propuesta, identificándose diferentes tipos de ellos como el hermenéutico y el estético. ${ }^{19}$ Es allí que los dispositivos de mediación permitirán reducir esas distancias de comprensión y, favorecerán el adecuado funcionamiento imaginario del visitante; ayudándolo, además, a desarrollar un interés por el arte contemporáneo. En la exposición analizada, la institución museal puso al servicio de los visitantes, varios medios escritos para facilitar la comprensión de la propuesta e, incluso, visitas guiadas en un horario específico. No obstante, tal como lo manifestó el público, fue precisamente la medición oral permanente (en sala) o con mayor frecuencia, la que más se echó en falta, puesto que la exposición resultó, incluso para el público advertido, "compleja":

Compleja, creo que [la exposición] amerita una visita guiada [...]. Estoy muy sorprendida de la exposición, ella corresponde a aquello que no se presenta habitualmente, [...] hay un esfuerzo pedagógico que ha sido hecho pero yo pienso que no es suficiente porque el tema es muy complejo y, el hecho de mezclar historia y el país [Colombia] través del arte contemporáneo colombiano que uno no conoce del todo y que es tan conceptual,...pienso que ameritaba...mediación, justamente. $^{20}$

Este es pues, uno de los puntos fundamentales a considerar al momento de planificar una exposición de arte contemporáneo pues nos encontramos con visitantes que tienen un diferente nivel de acercamiento a este tipo de propuesta. De hecho Eidelman ha identificado cinco tipos de visitantes: el indiferente, el curioso, el interesado, el amateur y, finalmente, el experto ${ }^{21}$ siendo estos dos últimos los considerados como el público "natural" de este tipo de propuesta cultural. Sin embargo, hay que tener en cuenta que siendo una exposición de arte colombiano en París, uno de los públicos interesados era el procedente de ese país, dentro del cual podíamos identificar todos los tipos de visitantes que Eidelman señala. $Y$ es precisamente en este grupo humano que vimos una mayor riqueza

18 Grassin lo define como el movimiento de "va y viene» que realizan los visitantes frente al objeto y su respectivo cartel, el cual forma parte del proceso para aprehender el objeto y así, realizar un aprendizaje. Cf. Grassin, 2007: 4-12.

19 Cf. Heinich, 1999: 151-162.

20 Traducción personal realizada de un fragmento de una entrevista $\left(\mathrm{N}^{\circ} 10\right)$ realizada a una visitante francesa a la salida de la exposición.

21 Cf. Eidelman, 1999: 163-192. 
de representaciones construidas, las cuales muchas veces fueron por un camino distinto al del análisis artístico. Al margen de este último punto sobre el que nos detendremos en las líneas siguientes, lo cierto es que la mayor parte del público comparte una misma dificultad: la comprensión del arte contemporáneo.

\section{Las representaciones evocadas ¿Cómo identificarlas? Algunos ejemplos}

El libro de visitantes constituye un instrumento apasionante para aproximarse y explorar el imaginario de los visitantes y, por ende, sus representaciones. En el medio francófono, varios estudios han sido realizados empleando esta fuente, sirviéndose de los métodos que proponen la Sociología, la Psicología y otras ciencias afines, permitiendo una cierta flexibilidad metodológica, aunque suponiendo una dosis de complejidad. De igual manera, el acercamiento a las representaciones evocadas se puede realizar a través de las entrevistas realizadas al salir de la exposición, las que, sin embargo, siempre conllevan límites en la información que de ellas se puede obtener. En ambos casos, no obstante, al decorticar los comentarios manifestados por el público, hay que considerar lo que Santander denomina "la opacidad del lenguaje", ya que se trata, en esencia de un análisis del discurso.

En el caso que presentamos, trabajamos con estos dos instrumentos, identificando diferentes tipos de representaciones, desde aquellas que recreaban lo que se consideraba ausente, hasta aquellas asociadas a la historia y la memoria histórica.

De los varios temas identificados en dichas fuentes recogidas, uno de los más interesantes fue el de la evocación de lo ausente que, en este caso, estuvo ligada a la falta de presencia de artistas mujeres en la muestra. Aunque no fue constante, un $1.07 \%$ de los visitantes, se expresaron en este sentido: "Otro gran silencio, la ausencia de las mujeres en esta expo [... |" (LdV), comentario de denuncia que se inserta en lo que algunas historiadoras del arte, como Nochlin, han identificado como una escritura "falocéntrica" de la historia del arte, debido a la mayoritaria presencia o visualización de los artistas, tanto expuestos, como citados en manuales de arte. Cabe destacar que en la exposición analizada sí se hace mención a una artista colombiana, bien posicionada en el mercado del arte internacional como es Doris Salcedo. No obstante, la mención a su instalación «Noviembre 6 y 7 n, aparece en la revista Hors-série ya citada, la cual no fue necesariamente consultada por el público (aunque se colocó un ejemplar a la salida de la muestra, al lado del Libro de visitantes y podía ser adquirida en la tienda del museo a 9 euros), pasando inadvertida, por ende, la mención a otros artistas colombianos -varones y mujeres-, y creando esta imagen de visión incompleta o parcial del arte colombiano, en los visitantes más advertidos.

También, otras de las representaciones evidenciadas fueron las asociadas a la historia y, también, a la memoria histórica. Una precisión habría que hacer antes de pasar a ver algunos ejemplos. Dentro del público, remarcamos que el público europeo de tipo grand public (público general), logró generalmente, distinguir entre una exposición con fin histórico (narrar la historia contemporánea de ese país) y una de tipo artístico (aunque en este caso, el arte esté inspirado en los hechos históricos), deteniéndose principalmente en reflexiones sobre el arte y sobre su satisfacción con la exposición; mientras que el público de origen latino y particularmente el colombiano, si bien podía hacer esa distinción en muchos casos, finalmente terminaba reflexionando sobre la historia reciente del país y las violencias en curso de superación:

La exposición de J. A. Restrepo me incomoda mucho A tal punto que tuve que salir a la siguiente exposición. Me recordó un poco las imágenes que uno ve en los noticieros cada dia...Creo que al fin y al cabo la exposición está muy bien hecha porque logra recordarme los malos episodios que existen en el país. (LdV). ${ }^{22}$

22 El subrayado es nuestro. 
Cabe decir que en muchos casos, se trataba de un público que declaró no conocer a los artistas y que no recordaba haber visitado sus exposiciones cuando vivían en Colombia; de manera que puede deducirse que el hecho de haber asistido a la exposición bajo análisis, estuvo motivado por un sentimiento de orgullo identitario. Distinto era el caso del público amateur y experto -europeo y latino- que declaró conocer la obra de estos artistas y cuyos comentarios enriquecían las reflexiones presentadas por la muestra, pues no se quedaban solo en la información adquirida en las salas, sino que tenían las claves necesarias para hacer comentarios adicionales sobre lo expuesto. En tales casos, tal como lo mencionaría DufresneTassé, estos últimos visitantes (que acudieron en cantidad minoritaria de acuerdo a nuestros datos), salieron del nivel emocional y del cognitivo para realizar un funcionamiento psicológico complejo y completo; situación que según esta investigadora, generalmente, llega solo en un $1 \%$ de los visitantes y que podría caracterizarse con el siguiente ejemplo:

[...] iqué pasada! Muchas gracias a los artistas. En cada uno vi una obra (por lo menos) que me impactó, muy enseguida lo del vídeo con el texto de Kierkegaard, de Restrepo, fantástico "encuentro fortuito" entre dos realidades que surgen de repente como una evidencia, un fantástico guiño del universo a través del ojo del artista que en ese momento "Sabe" mirar y esculpe una verdad (como Miguel Ángel) en el mármol invisible que nos rodea, en cada instante, con sus imágenes aparentemente anónimas. iChapó artista! Lo mismo con la "Línea del destino" de Muñoz, al estilo de Buñuel. Una obra diría perfecta, muy enseguida también, la mano, la cara, y el agua que poco a poco desaparece... Las grietas de Echevarría como un grito en el silencio, el grito de una consciencia agrietada que yace en cada uno de nosotros. Bueno y al caballo, vivo moribundo o fantasma encarnado, en ese paraje infinito e indefinido como nuestra fe en un paraíso vago y confuso... iincreible! Sin olvidar los trozos de vida y carne que se agitan en la mirada de Rojas pero también en su corazón, en su pecho, que me asombra su humanidad...En fin, muchas gracias, por ese gran momento de arte y vida fue calidad. Muchas gracias. (LdV).

Volviendo al público general colombiano, muchas veces sus reflexiones giraban en torno a la no contemporaneidad de la violencia mostrada por las obras y, el tiempo actual; así como sobre la visión estereotipada que consideraban existe sobre su país, en el extranjero. De alguna manera, este tipo de comentarios se alzaban como un pedido de olvido y de superación de un pasado violento, lo cual revela, según entendemos, un problema relacionado con la aceptación de la historia y el manejo de la memoria histórica:

La historia se debe recordar para no repetir, muchos estamos aquí para olvidar y no repetir, pero es tanto lo que nos repiten que es como si quisieran que se repita. Para exponer aquí, hay quienes eligen. Si! Los artistas son interesantes, pero no la representación de nuestro arte ni la realidad de nuestra Colombia, la que queremos vivir, donde también existen las mujeres, los indígenas, los negros y otros lentes para ver nuestra patria. Hasta cuándo nos van a "moldacar" a las Nuevas generaciones la herencia de un odio y una violencia ya tan vista, hasta el punto de dar la impresión de ser disfrutada y lo único que permite mostrarnos y creer conocernos". Colombia es diversa, es muchas cosas. Conózcanla! y verán. Laura 2013. Una colombiana. (LdV) ${ }^{23}$.

Esto nos revela que una exposición de arte contemporáneo donde la obra expuesta es fundamentalmente fotográfica (con fin artístico), puede ser leída por el público general como documental (sin que con ello se entienda que las de este último tipo, no puede tener un carácter artístico, aunque no sería este su fin primero). Precisamente, una de las 
interpretaciones hechas por el público fue que esta muestra reducía al país a sus conflictos políticos, tal como manifestó un visitante a través de un dibujo, los cuales son habituales en los libros de visitantes. En este caso, un dibujo vale más que mil palabras y, debido a las reglas ortográficas seguidas (apertura y cerrado de signo de interrogación, cuando en el francés solo se usa el cierre), evidencia que un visitante latino (¿colombiano quizás?) ha sido quien hizo esa lectura final de la exposición:

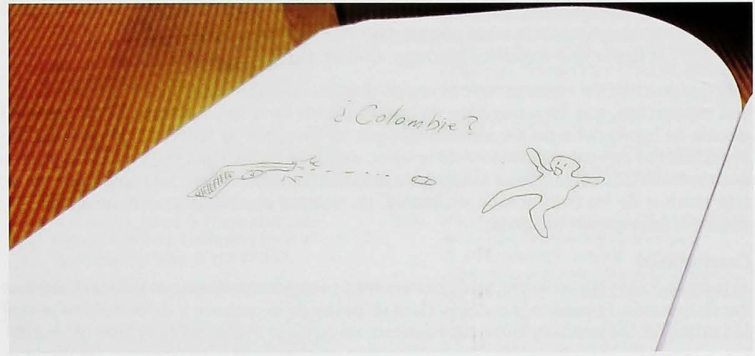

Fig. 3.- Uno de los gráficos consignados por los visitantes en una página del libro de visitantes. Fotografia de C.V.P.

Paul Ricoeur ha explicado lo que él ha calificado como la "política de la justa memoria y el olvido», la cual comporta la realización de un "duelo colectivo». Según este connotado intelectual, existen tres tipos de abuso de la memoria: la memoria impedida, la memoria manipulada y la memoria olvidada. Según Echavarría, uno de los artistas expuestos, Colombia es un país que adolece de Alzheimer con relación a su historia. ${ }^{24}$ Estos tipos de comentarios nos revelan que los artistas lograron en el público colombiano, la reflexión que ellos buscaban producir en el observador, con sus obras. No obstante, este tipo de comentarios -ver ejemplo en cita $\mathrm{N}^{\circ} 24$, revelan que hay una dificultad, aún palpable, de hablar o ser confrontados con sus traumas históricos; pero también nos permiten reflexionar sobre las posibilidades que abre la vía del arte, para realizar ejercicios de memoria histórica que ayuden a superar episodios dolorosos. Hay que anotar, sin embargo, que también identificamos el caso de visitantes que reclaman un deber de memoria en el pueblo colombiano como primer paso de la reconstrucción de la vida nacional. ${ }^{25}$

En cuanto al público europeo que se manifestó sobre el tema comentado, constatamos que este fue en menor cuantía y con menor apasionamiento, probablemente por la distinta mirada que tienen de los temas que vehiculan las obras expuestas: «Beautés colombienne $\&$ ravages actuels» ("Bellezas colombianas y desastres actuales". LdV); o, incluso: " Magnifique photographies et installation. C'est véritablement la vision d'un autre monde. Nous sommes ici si protegés” ("Magnifica fotografia e instalación. Verdaderamente es la visión de otro mundo. Aquí nosotros estamos protegidos". LdV). Como se ve, las vivencias, los recuerdos y la cultura cotidiana o institucional que el público pre-posee al ir a la exposición, influyen en la lectura de la obra y, por consiguiente,

24 Cf. «En conversación: Juan Manuel Echavarría y Laurel Reuter» (entrevista). Agosto, 2004. En el sitio internet del artista colombiano. http://www.jmechavarria.com/ 
de la muestra en su conjunto. En ese sentido, el público latino también se manifestó sobre la posible dificultad de que el público francés pudiera comprender, cabalmente y correctamente, este tipo de obras, sin contar con un marco contextual abundante:

Muy bella exposición, interesante concepción del espacio. Diferentes perspectivas de los diferentes artistas. Maravilloso que el Musée du Quai Branly haya volteado su mirada a la escena artística colombiana. Me pregunto únicamente por la recepción del público francés. Las obras aquí expuestas exigen de un cierto conocimiento de la realidad colombiana. Sin un tal contexto ¿Podrán entender la complejidad de estas propuestas? Pienso particularmente en El Caballero de la fe por José Alejandro Restrepo. Gracias. (LdV). ${ }^{26}$

Hay que precisar, sin embargo, que el museo dispuso un cartel temático en la primera unidad expográfica, que daba una clave de lectura basada en la historia colombiana desde la década de los 40 del siglo XX; información que fue brindada de manera más detallada en el documento de acompañamiento de la visita, donde se incluyó una línea cronológica con hechos históricos colombianos asociados a la violencia política. Pero tal como lo demuestran muchos de los comentarios analizados, no siempre el público se detiene a leer con detalle la información brindada.

\section{Conclusiones}

Al margen de los diferentes tipos de comentarios recogidos, toda una dinámica discursiva queda revelada. El público pues, deja claro su deseo de expresarse y de comunicarse con la institución, los artistas y entre ellos mismos, tal como se evidenció en el libro de visitantes, a través de los comentarios que respondían, contradecian o reafirmaban los vertidos anteriormente, lo que demuestra que este recurso, puede convertirse en un espacio de debate y de comunicación. Visto desde la perspectiva de la institución, de ser aprovechado el libro de visitantes permitiría repensar las futuras exposiciones y actividades a proponer, de manera que el diálogo con los visitantes sea más fluido; así como también, atender a las diferentes demandas que aparecen, desde aquellas que van asociadas al confort en el museo (servicios, asientos, iluminación, entre otras).

Es así como el considerar y explorar el funcionamiento psicológico que cada tipo de visitante realiza en una exposición resulta pues, fundamental para, en primer lugar, entender qué es lo que constituiría una óptima experiencia museal en cada público y así poder replantear las políticas institucionales a fin de acercar, cada vez más, esta institución al público habitual, así como al potencial. De ser así, los objetivos de aprehendizaje, pero también de fidelización, podrían realizarse. En segundo lugar, el uso de estos tipos de materiales (libro de visitantes, entrevistas...) para explorar el imaginario de los visitantes, se revela un útil fabuloso para comprender y atender problemas de índole social y cultural subyacentes como también, aquellos concernientes al acercamiento y la comprensión del arte contemporáneo. 


\section{Bibliografía}

Davallon, Jean

1992 "Le musée est-il vraiment un média ?". Public et Musées. Regards sur l'évolution des musées, II (2) : 99- 123.

Desvallées, André y Maraisse, François (dir.) "Conceptos claves en Museología". (2010) http:/icom.museum/fileadmin/ user upload/pdf/Key Concepts of Musēology/Museologie Espagnol BD.pdf [Consulta: 20 julīo 2014].

Durán Gamba, Mildred

2009 «Au-délà de la beauté: la transfiguration de la violence dans l'oeuvre de quatre artistes colombiens contemporains. Jaime Ávila, Juan Manuel Echavarría, Óscar Muñoz et Miguel Ángel Rojas ». Histo.Art. Revue de l'École doctorale d'Histoire de l'art. Université Paris 1 Panthéon-Sorbonne. 1: 147-162.

Dufresne-Tassé, Colette, Sauvé, Monique, Banna, Nadia, et alii

2000 Fonctionnement imaginaire, culture du visiteur et culture exposée par le musée. En Diversité culturelle. Distance et Apprentissage. Cultural Diversity. Distance and Learning. Diversidad cultural. Distancia y Aprendizaje. Dufresne-Tassé, Colette (ed.): 136-156. Québec, ICOM CECA.

Eidelman, Jacqueline

1999 La réception de l'exposition d'art contemporain. Hypothèses de collection». Publics et Musées. Le regard au musée, 16: 163-192.

Grassin, Anne-Sophie

2007 aLe jonglage objet-cartel». La lettre de I'OCIM. 110:4-12.

Heinich, Nathalie

1999 "Les rejets de l'art contemporain ». Publics et Musées. Le regard au musée. 16, $1999: 151-162$.

Moscovici, Serge

2004 La psychanalyse, son image et son public. París, Presses Universitaires de France.
Poli, Marie-Sophie, Houbart, Danielle

2007 "L impact du discours muséographique sur les visiteurs de I' exposition L' Art italien et la Metafisica. Le temps de la mélancolie 1912-1935, présentée au musée de Grenoble, de mars à juin 2005. En, La place des publics. De I' usage des études et recherches par les musées. Eidelman, Jacqueline, Roustan, Mélanie, Goldstein, Bernadette : 185-198. París, La documentation française

Sader, Emir, Jinkings, Ivana (Coord.)

2008 Latinoamericana. Enciclopedia contemporánea de América Latina y el Caribe, Madrid, CLACSO, AKAL.

Schuller, P.

2000 Museum of International Contemporary Art: Cultural Diversity Guaranteed !?! ». En Diversité culturelle, distance et apprentissage. Cultural Diversity: Distance and Learning. Diversidad Cultural, Distancia y Aprendizaje, Dufresne- Tassé, Colette (ed.): 76- 83. Québec, ICOM CECA.

2004 "En conversación: Juan Manuel Echavarría y Laurel Reuter» (agosto, 2004). En Sitio internet de Juan Manuel Echavarría http://www.jmechavarria.com/ [Consulta: 10 marzo 2014].

2004 Documental Plástica. Arte contemporáneo en Colombia. "Lo que puede un cuerpo: performance» Cap. 7. (2004). http:// youtu.be/OOUKcZiOS-g Ministerio de Cultura de Colombia. El vicio producciones. [Consulta: 15 abril 2014].

2013 Revista Hors-série. Beaux Arts magazine. Nocturnes de Colombie. Images contemporaines. (2013) París.

2014 Casa Daros Latinamerica http:// www.daros-latinamerica.net/index zh.php?i=941 [Consulta: 15 abril 2014 ]. 
